\title{
Yenilikçi, Destekleyici ve Bürokratik Örgüt Kültürünün Pazar Odaklılık Üzerine Etkisi: Otel İşletmeleri Üzerine Bir Çalışma
}

\section{The Effect of Innovative, Supportive and Bureaucratic Organization Culture On Market Orientation: An Example of Hotel Organizations}

\author{
Ozan Çatır ${ }^{\text {a** }}$ \\ a Dr. Öğr. Üyesi, Uşak Üniversitesi, Ulubey Meslek Yüksekokulu, Seyahat, Turizm ve Eğlence Hizmetleri Bölümü, Uşak/ Türkiye. \\ ORCID: 0000-0003-3168-7338
}

\section{MAKALE BILGİSI}

Makale Geçmişi:

Başvuru tarihi: 20 Eylül 2018

Düzeltme tarihi: 18 Aralık 2018

Kabul tarihi: 02 Ocak 2019

Anahtar Kelimeler:

Yenilikçi Kültür

Destekleyici Kültür

Bürokratik Kültür

Pazar Odaklılık

\section{A R T ICLE INFO}

\section{Article history:}

Received 20 September 2018

Received in revised form 18 Desember 2018

Accepted 02 January 2019

\section{Keywords:}

Innovative Culture

Supportive Culture

Bureauctratic Culture

Market Orientation

\section{ÖZ}

Bu çalışmanın amacı, yenilikçi, destekleyici ve bürokratik kültürün otel işletmeleri bağlamında pazar odaklılık üzerindeki etkilerini incelemektir. Bu araştırma için yöntem, tanımlayıcı olarak tasarlanmıştır. Uygulama için 312 anket formu dağıtılmış ve elde edilen 242 anket formundan 226 tanesi değerlendirmeye uygun görülmüştür. Anketlerden elde edilen veriler düzenlenerek istatistik paket programında uygun analizler (ortalama, standart sapma, faktör analizi, regresyon) yapılarak yorumlanmıştır. Çalışmanın sonuçlarına göre, yenilikçi ve destekleyici örgüt kültürü boyutlarının pazar odaklılık üzerinde pozitif yönlü bir etkisinin olduğu tespit edilmiştir. Ayrıca, otel işletmeleri için mevcut olan örgütsel planlama ve pazarlama seçeneklerinin geliştirilmesi ve örgüt kültürünü şekillendirmeye çalışan yöneticilere pazar odaklılığın uygulanması ile ilişkili davranışlara rehberlik edilmesi gerekliliği vurgulanmıştır.

\section{A B S T R A C T}

The aim of this study is to examine the effects of innovative, supportive and bureaucratic culture on market orientation in the context of hotel businesses. The method for this research was designed as descriptive. 312 questionnaires were distributed and 226 of 242 questionnaires were evaluated. The data obtained from the questionnaires were edited and interpreted in the statistical package program by performing appropriate analyzes (mean, standard deviation, factor analysis, regression). According to the results of the study, innovative and supportive organizational culture dimensions have a positive effect on market orientation. In addition, it is emphasized that the existing organizational planning and marketing options for hotel businesses should be developed and the managers who try to shape the organizational culture should be guided by the behaviors related to the application of market focus

\section{Giriş}

Örgütlerin başarılı olmalarında örgüt kültürü ve pazar odaklılık önemli iki kavram olarak görülmektedir. Örgütlerin pazar odaklı bir yaklaşım sergilemesi, benimsemiş olduğu örgüt kültürüne bağlıdır. Örgüt kültürü, işletmenin tüm bölümlerini etkileyen bir unsurdur (Leisen, Lilly ve Winsor, 2002). Örgüt kültürü boyutlarının, pazar odaklılığı nasıl etkilediğine yönelik az sayıda çalışmaya rastlanılmıştır (Kirca, Jayachandran ve Bearden, 2005;
McClure, 2010). Araştırmacılar, iç örgütsel değişkenler üzerindeki araştırma eksikliğinin hem pazar odaklılığının

hem de bunun nasıl uygulanacağının tespit edilmesini sınırlandırdığını iddia etmektedirler (Gebhardt, Carpenter ve Sherry, 2006; Gao, 2017). Pazar odaklılığı ve örgüt kültürü çalışmalarının nadir olması göz önüne alındığında (Deshpande ve Farley, 2004; O'Cass ve Viet Ngo, 2007), örgüt kültürünün pazar odaklılığına etkisinin açıklamak zorunlu olmaktadır (Kirca vd. 2005; McClure, 2010). Bu

\footnotetext{
* Sorumlu yazar/Corresponding author

e-posta: ozan.catir@usak.edu.tr
} 
araştırmanın amacı, örgüt kültürünün pazar odaklılık üzerindeki etkilerini belirlemektir.

$\mathrm{Bu}$ çalışmada öncelikle pazar odaklılık ve örgüt kültürü ve örgüt kültürü boyutları açıklanmış ve daha sonraki bölümde çalışmanın yöntem kısmına değinilmiş ve Uşak ilinde faaliyet gösteren otel işletmeleri üzerinde yapılan uygulamaya yönelik bulgular sunulmuştur. Sonuç kısmında ise çalışmanın genel bulgularından bahsedilerek, araştırmacılara ve uygulamacılara öneriler geliştirilmiştir.

\section{Kavramsal Çerçeve}

Bu bölümde çalışmanın konusu olan pazar odaklılık ve örgüt kültürü kavramlarının teorik alt yapısı ve bu teorilerden yola çıkarak oluşturulan hipotezler verilmiştir.

\subsection{Pazar Odaklilık}

Pazar odaklılık literatürde önemli konulardan birisidir. $\mathrm{Bu}$ konuda iki temel ve farklı yaklaşım bulunmaktadır. İlk yaklaşım Narver ve Slater'in (1990) yaklaşımıdır. Bu yaklaşıma göre kültürel bir bakış açısı benimsenmekte ve pazar odaklılığı alıcılar için üstün değer yaratmak için gerekli olan, en etkili ve verimli faaliyetler üreten örgüt kültürüne dayandırmaktadır. Narver ve Slater (1990) pazar odaklılığın üç faktörünün olduğunu ileri sürmüşlerdir. Bunlar, müşteri odaklılık, rakip odaklılığı ve işlevler arasında koordinasyondur. Diğer yaklaşım ise Kohli ve Jaworski (1990) tarafindan ifade edilmiştir. Bu yaklaşımda, müşterinin mevcut ve gelecekteki ihtiyaçlarına odaklanan, örgüte yayılım sürecine, pazarlama stratejilerine ve piyasa tepkisine dayanan bir pazar odaklılığı benimsenmiştir. İki yaklaşımda, tüketicilerin talep ve ihtiyaçlarını belirlerken, ticari politikaları tanımlamadaki stratejilerin dikkate alınması gerektiğini ifade etmektedir. Ancak her yaklaşım farklı bir odağ 1 benimsemektedir. Pazar odaklılığ kavramsallaştırılması açısından hem de örgütte "işlevsel koordinasyon" ve "bilgi yaygınlaştırma" gerektiren bir bölüm örgütlenme yapısı için yalnızca küçük ölçekli ve orta ölçekli işletmeler için geliştirilmiștir (Herrero vd., 2013). Bu araştırmada Kohli ve Jaworski (1990)) tarafından önerilen pazar odaklılığı yaklaşımı benimsenmektedir. Ayrıca Chen ve Myagmarsuren'in (2013) turizm işletmelerine özgü yaptığ 1 çalışma dikkate alınmış, bu bakımdan küçük işletmeler için geçerli olan müşteri odaklılık ve rakip odaklılık boyutları da çalışma kapsamına alınmıştır.

\subsection{Otelcilik Sektöründe Pazar Odaklılı̆̆1 Kavramı}

Otelcilik sektöründe, pazar odaklılığı kavramı; bilgi ve iletişim teknolojisi (Pena, Jamilena ve Molina, 2013), pazar stratejisi, iş stratejisi (Wu, 2004), rekabet üstünlüğü (Zhou, Brown, ve Dev, 2009), toplam kalite yönetimi (Wang, Chen, ve Chen, 2012) ve turist (Pena, Jamilena ve Molina, 2012) gibi çeşitli değişkenlerle ilişkili olarak incelenmiştir. Genel olarak, otel yöneticilerinin, müşterinin ihtiyaçlarını daha iyi karşılamak ve iş performans hedeflerini gerçekleştirmek için pazar odaklı olmaları gerektiği vurgulanmıştır. Pazar odaklılığına daha fazla önem verilmesi, hızla değişen piyasa koşullarına uyum sağlamak açısından sezgisel olarak iyi bir önlem olmaktadır (Wang vd., 2012).

Oteller, birçok başka hizmette olduğu gibi, üretim ve tüketimin eşzamanlılığ , hizmet performansının heterojenliği ve bozulabilirlik gibi özellikleriyle emek yoğun bir sektördür
(Parasuraman, Zeithaml ve Berry, 1985). Bundan dolay1 üretim sektörüne göre hizmet sektöründe müşteri tatminin sağlanabilmesi kişiye yönelik hizmet sunmaya bağlıdır (Anderson, Fornell, ve Rust, 1997). Piyasa odaklılık kavramının uygulanma derecesine ve/veya küçük işletmeler tarafından kullanılmasına ilişkin literatürde az sayıda çalışma bulunmaktadır (Stokes, 2000; Becherer, Halstead, ve Haynes, 2003). Hizmet sektöründe olanlar da dahil olmak üzere birçok küçük işletme, kaynaklara yetersiz (örneğin zaman, emek, uzmanlık, finans) erişim (Didonet, Simmons, Diaz-Villavicencio ve Palmer, 2012) nedeniyle piyasa odaklılığı ile ilişkili davranışları benimseme becerisi (Becherer vd., 2003) yeterli değildir. Örneğin, önemli kaynaklara erişimin olmaması, küçük otel işletmelerinin karmaşık süreçlere güvenmesi, pazarın ihtiyaçlarını belirlemeye yönelik geleneksel pazarlama görüşünün benimsenmesi ve yeni ürün ve hizmetlerin geliştirilmesi (Stokes ve Blackburn, 1999) kabiliyetlerini kısıtlamaktadır.

\section{3. Örgüt Kültürü}

Smircich'e (1983) göre, örgüt kültürü, bir örgütte insanların davranışı ve insanların bu davranışlara verdiği anlamdır. Bunlar "norm ve uygulamalar" ile ilgili davranışlardır (Schein 2010).

Schein (2010: 26-36) örgüt içindeki gözlemcinin görebileceği yapıtlar, efsaneler ve benimsenen değerler olmak üzere üç kültürel olgu seviyesini tanımlamıştır. Her biri, örgüt kültürü anlayışına katkıda bulunur. Yapıtlar, örgütün tanımlanabilir unsurlarıdır (yani üniformalar, dil vb.). Yapıtlar, mesleki jargon, davranışlar ve görünüşün kullanılması yoluyla örgüt dışı olanlara kişisel kimlik kazandırır. Örgüt efsaneleri, üye olan ve üye olmayan kullanıcıları tanımlamaya yardımcı olur. Benimsenen değerler, genellikle resmi felsefelerde ifade edilen davranış kurallar1/politikalar ve profesyonellik ve prosedürler gibi kimliğin ifadeleridir. Benimsenen değerler, genellikle örgüt kültürü için kendini güçlendirir. Örgütsel bir düşünme şeklini tanımlamaya başlarlarken, örgütü zorlukla yönlendirirler. Varsayımlar, genellikle bilinçsiz olan, ancak kültürün özünü oluşturan derin, gömülü, kabul edilmiş davranışlardır. Bu seviye örgüt kültürüne çok iyi entegre olduğundan içeride olanlar tarafindan dahi tanınması zordur. Örgütsel varsayımlar, örgütün kendi gerçekliğini algılama, düşünme ve algılama biçimidir (Schein 2010; 26-36).

Örgüt kültürü çalışması için çeşitli planlar, boyutlar ve düzeyler önerilmiş olsa da (Wallach, 1983), üç boyut örgüt kültürü boyutları olarak tanımlanmıştır (Berson, Oreg ve Dvir, 2008). Wallach (1983) bir örgütün kültürünün bürokratik, yenilikçi veya destekleyici olarak üç boyutunun olduğunu ileri sürmüştür. McClure $(2010 ; 515)$ kullandıkları etiketler farklı olsa da, tanımladıkları fenomenlerin çok benzer olduğunu ifade etmiştir. Bu türler karş1lıklı olarak değil, baskın olarak kabul edilirken, bir örgütün kültürü bu üç boyutun birleşmesiyle belirlenebilir (Wallach, 1983). Zamanla, bir tür hâkim olmakla birlikte, herhangi bir zamanda, bir örgüt çeşitli kültür unsurlarına sahip olabilir ve farklı kültür tipleri ile farklı derecelerde ilişkili özellikler gösterebilir (Deshpande vd., 1993). Wallach'a (1983) göre, bürokratik kültür örgütlü, sistematik, prosedürel ve düzenlenmiş bir çalışma ortamını ifade eder. Bu boyuttaki örgütler esneklikten yoksun kalmakta, verimliliği, öngörülebilirliği ve tutarlılığı vurgulamaktadır (Wallach, 
1983; Berson vd., 2008). Yenilikçi kültür, yaratıcı, sonuç odaklı ve zorlayıcı bir çalışma ortamı anlamına gelmektedir. $\mathrm{Bu}$ boyut, zorlayıcı ve riskli çalışanların ilgisini çeken girişimci ve firsatçı bir ortamı içermektedir (Ireland, Hitt, ve Sirmon, 2003; Berson vd., 2008). Destekleyici kültür, insan odaklı ve cesaret verici bir çalışma ortamında kendini gösterir. Bu tür kültürler, çalışanlar arasındaki açık ilişkileri kolaylaştırır ve adil, arkadaşça ve yardımsever bir çalışma ortamı sağlamaktadır (O'Reilly, Chatman, ve Caldwell, 1991). Araştırmanın hipotezleri aşağıda sunulmuştur.

H1: Yenilikçi örgüt kültürü pazar odaklılığını pozitif yönde etkiler.

H2: Destekleyici örgüt kültürü pazar odaklılığını pozitif yönde etkiler.

H3: Bürokratik örgüt kültürü pazar odaklılığını negatif yönde etkiler.

\section{Yöntem}

$\mathrm{Bu}$ bölümde araştırmada kullanılan ölçekler, güvenilirlik, faktör ve normal dağılım analizlerine yer verilmiştir.

\section{1. Örgüt Kültürü Ölçeği}

Wallach (1983) örgüt kültürünü üç farklı boyutta ölçmüştür. $\mathrm{Bu}$ boyutlar, bürokratik, yenilikçi ve destekleyici örgüt kültürüdür. Wallach (1983) tarafından geliştirilen ölçek önce İngilizce'den Türkçe'ye çevrilmiş daha sonra Türkçe'den İngilizce'ye geri çeviri yapılarak oluşturulmuştur. Wallach (1983) tarafından geliştirilen örgüt kültürü endeksi 24 maddeye (her boyut için 8) sahiptir. Likert tipi (Çoğu zaman örgütümü tanımlar: 5; Örgütümü tanımlamıyor: 1) ölçek kullanılmıștır. Örgüt kültürü endeksi, 0,70 ile 0,89 arasında değişen güvenilirlik katsayıları bulunan diğer araştırmacılar tarafından geniş çapta benimsenmiş ve onaylanmış bir ölçektir (Chen, 2013; McClure, 2010).

\subsection{Pazar Odakl1lık Ölçeği}

Çalışmada pazar odaklılığı Deshpande ve Farley (1998) tarafından geliştirilen 10 maddelik pazar odaklılık ölçeği kullanılarak ölçülmüştür. $\mathrm{Bu}$ ölçekte de Türkçe'den İngilizce'ye İngilizce'den Türkçe'ye çeviri yöntemi kullanılmıştır. Maddeler, "kesinlikle katılmıyorum" ve "kesinlikle katılıyorum" şeklinde likert tipi olarak beş puanlık ölçek ile ölçülmüştür.

\subsection{Güvenilirlik ve Geçerlilik Analizi}

Ölçüm modeli analizi doğrultusunda pazar odaklılı̆̆ 10 maddeyle temsil edilmiştir. Örgüt kültürü ölçeğinde yenilikçi kültür boyutu 8 , destekleyici kültür boyutu 8 ve bürokratik kültür boyutu 8 maddeyle temsil edilmiştir. (Tablo 1). Güvenilirlik Cronbach alfa temelinde değerlendirilmiştir. Tüm alfa katsayıları 0.70 katsayısını aştıği için çalışma yapılarının güvenilirliği kabul edilmiştir (Tablo 1). Yakınsak geçerlilik, her bir yapı için diğer yapılarla olan korelasyonuna karşı ortalama Varyans Özeti incelenerek oluşturulmuştur. Her bir madde için standart faktör yüklemeleri de incelenmiştir. Tüm maddeler, faktör yüklemeleri 0.40 ile 0.90 arasında değişen faktörlere göre önemli derecede yüklenmiştir $(\mathrm{p}<0.001)$. Ortalama varyanslar 0.50 'i aşmıştır. $\mathrm{Bu}$ sonuçlara göre ölçekler güvenilir ve geçerlidir.

Tablo 1 Maddeler, Güvenilirlik Katsayısı, Ortalama Varyans

Faktör Yükleri

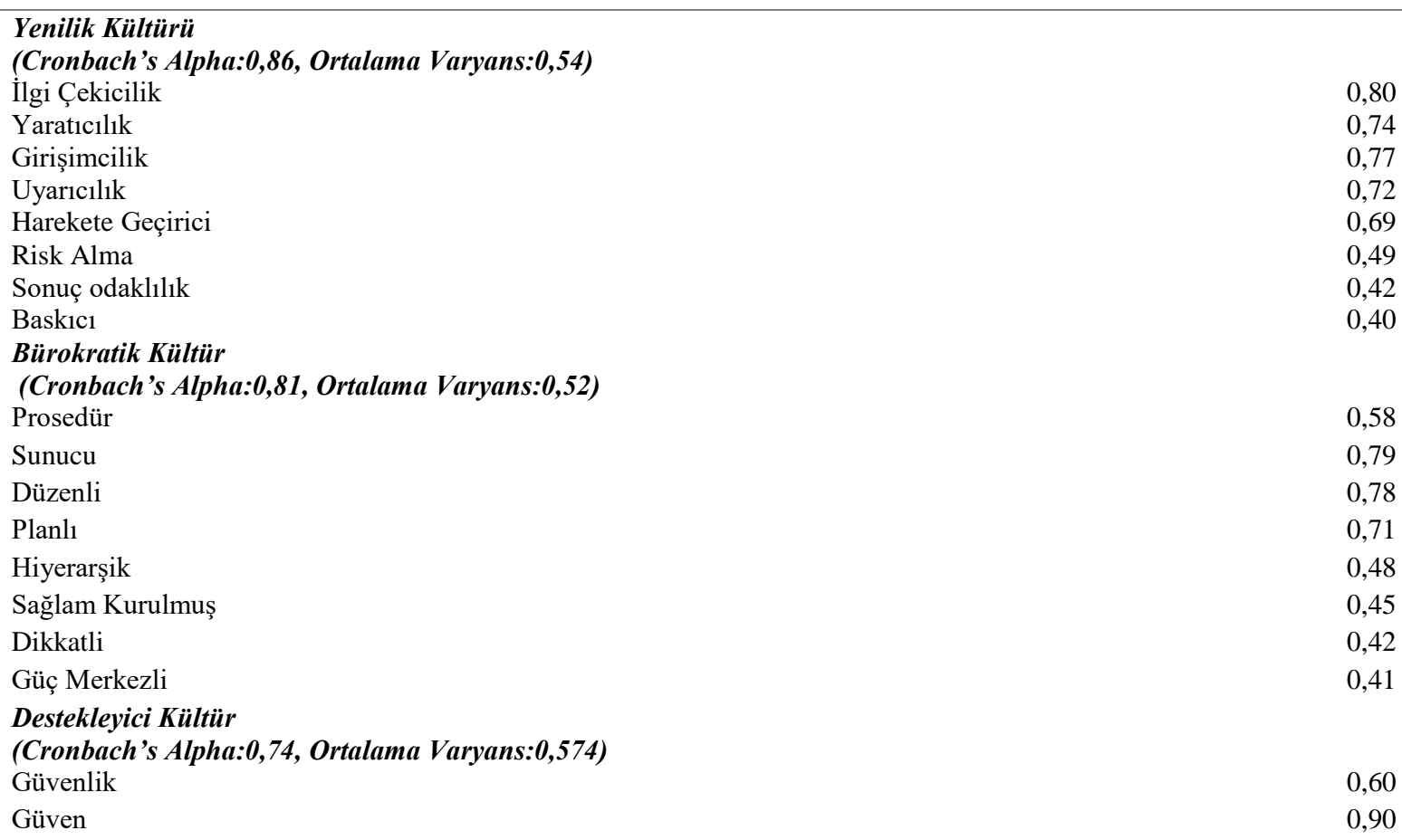




$\begin{array}{lr}\text { Cesaret Verici } & 0,71 \\ \text { İşbirlikçi } & 0,64 \\ \text { İlişki Merkezli } & 0,58 \\ \text { Sosyal } & 0,57 \\ \text { Kişisel Özgürlük } & 0,47 \\ \text { Adalet } & 0,45 \\ \text { Pazar Yönlendirme } & \\ \text { (Cronbach's Alpha:0,90, Ortalama Varyans:0,55) } & 0,75 \\ \text { İş hedeflerimiz öncelikle müşteri memnuniyetiyle sağlanır } & 0,79 \\ \text { Rakiplerimizden daha fazla müşteri odaklıyız } & 0,76 \\ \text { Rekabet avantajı için stratejimiz, müşteri ihtiyaçları konusundaki anlayışımıza dayanmaktadır. } & 0,71 \\ \text { Bu işletmenin esas görevinin müşterilere hizmet etmek olduğuna inanıyoruz } & 0,73 \\ \text { Başarılı ve başarısız deneyimler hakkında özgürce bilgi veririz } & 0,69 \\ \text { Geliştirmek ve yeni yollar bulmak için müşterilerimizi ve rakiplerimizi sürekli olarak izliyoruz } & 0,76 \\ \text { Müşteri memnuniyetine ilişkin veriler, her seviyede düzenli olarak izlenir. } & 0,81 \\ \text { Müşteri hizmetleriyle ilgili düzenli ölçümler yapıllmaktadır. } & 0,70 \\ \text { Hizmetlerimizin kalitesini değerlendirmek için yılda en az bir kere müşterilerimize anket yapıyoruz } & 0,72 \\ \text { Müşteri memnuniyetini sistematik olarak sıklıkla ölçeriz } & \end{array}$

$* \mathrm{p}<0,001$

\section{4. Örneklem ve Veri Toplama}

Araştırmanın evrenini Uşak'ta faaliyet gösteren 3 ve 4 yıldızlı otel işletmelerinde çalışanlar oluşturmaktadır. Araştırmada veri toplama aracı olarak "anket tekniğinden" yararlanılmıştır. Bu bağlamda 312 adet anket formu otel işletmelerine dağıtılmıştır. Yapılan ve geri toplanan

Tablo 2: Katılımc1lara Ait Tanımlayıcı İstatistikler

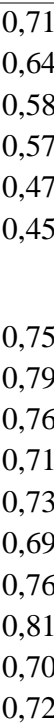

0,72

\begin{tabular}{lll}
\hline Cinsiyet & Çalışan (n) & Yüzde (\%) \\
\hline Erkek & 132 & 58,41 \\
Kadın & 94 & 41,59 \\
Toplam & 226 & 100 \\
\hline Yaş & Çalışan (n) & Yüzde (\%) \\
\hline $16-25$ & 120 & 53,10 \\
$26-35$ & 61 & 26,99 \\
36 ve üzeri & 45 & 19,91 \\
Toplam & 226 & 100 \\
\hline Öğrenim Durumu & Çalıșan (n) & Yüzde (\%) \\
\hline İlkokul ve ortaokul & 35 & 15,49 \\
Lise & 91 & 40,27 \\
Önlisans & 58 & 25,66 \\
Lisans ve lisansüstü & 42 & 18,58 \\
Toplam & 226 & 100.0 \\
\hline Hizmet Süresi & Calıșan (n) & Yüzde (\%) \\
\hline$<10$ y1l & 108 & 47,79 \\
11 ile 20 y1l aras1 & 73 & 32,30 \\
21 ile 30 yıl aras1 & 27 & 11,95 \\
31 yıl üstü & 18 & 7,96 \\
Toplam & 226 & 100 \\
\hline
\end{tabular}

Tablo 2'ye göre, çalışanların \% 58,41'u erkek, \% 41,59'u kadındır. Çalışanların \% 53,10’u 16-25; \% 26,99'u ise 2635 yaşları arasındadır. Araştırmaya katılan çalışanlarının çoğunluğunun genç olduğu sonucuna ulaşılabilir. Çalışmaya katılanların \% 40,27'sinin lise mezunu \% 25,66'sının ise önlisans mezunu olduğu görülmektedir. Hizmet süresiyle ilgili bulgular incelendiğinde, çalışanların $\%$ 47,79'unun 10 yılın altında, \% 32,30'unun ise 11-20 yıl arası görev yaptıkları görülmektedir.

3.5. Normal Dağılım Analizi anketlerin sayısı toplam 242'dir. Kontrol aşamasının sonunda 17 yanlış veya eksik bilgi içeren anketler elenmiştir. Hatalar veya eksik bilgileri içeren anketler hariç, otelden 226 geçerli anket analiz edilmiştir. Katılımcıların özellikleri Tablo 2'de sunulmuştur.
Verilerin normallik varsayımlarını karşılayıp karşılamayacağını görmek için çarpıklık ve basıklık değerleri incelenmiştir. Sonuçlar, göstergelerin tümünün çarpıklık değerleri için 0,90 ile 0,14 arasında ve basıklık değerleri için 0,76 ile 0,95 arasında değiştiği görülmüştür. $\mathrm{Bu}$ değerlere göre normallik varsayımı sağlanmıştır.

\section{Bulgular ve Yorumlar}

$\mathrm{Bu}$ bölümde hipotezlerin test edilmesi amaciyla regresyon analizi bulgularına yer verilmiştir. 


\section{1.Hipotezlerin Test Edilmesi}

Regresyon analizi, örgüt kültür tiplerinin pazar odaklılığına etkilerini tahmin etmek için kullanılmıştır. Örneklem sayısı az olduğu için yapısal eşitlik modeli yerine regresyon analizi yapılmıştır. Pazar odaklılı̆̆ 1 bağımlı değişken olarak belirlenmiş ve örgüt kültürü boyutları ise $\mathrm{H}_{1}, \mathrm{H}_{2}, \mathrm{H}_{3}$ hipotezlerinin incelenmesinde bağımsız değiş̧en olarak ele alınmıştır. Tablo 3 'te regresyon analizi sonuçları sunulmuştur. Tablo 3'e göre yenilikçi örgüt kültürünün pazar odaklılık üzerindeki etkisini belirlemek üzere oluşturulan birinci hipotez $\mathrm{H}_{1}$ : "Yenilikçi örgüt kültürü pazar odaklılığını pozitif yönde etkiler." hipotezi \% 5 anlamlılık düzeyinde $(p=0,000)$ kabul edilmiştir. Pazar odaklılığındaki değişimin \% 43,1'lik kısmının yenilikçi örgüt kültüründen kaynaklandığı, yenilikçi örgüt kültüründeki bir birimlik artışın, pazar odaklılığını 0,892 birim arttırdığı belirlenmiştir. Yenilikçi bir örgüt kültürünün benimsenmesinin otellerin pazar odaklılı̆ğın arttıracağ 1 söylenebilir.

Destekleyici örgüt kültürünün pazar odaklılık üzerindeki etkisini belirlemek üzere oluşturulan ikinci hipotez $\mathrm{H}_{2}$ :

Tablo 3. Regresyon Analizi Bulguları
"Destekleyici örgüt kültürü pazar odaklılığını pozitif yönde etkiler." hipotezi $\% 5$ anlamlılık düzeyinde $(\mathrm{p}=0,000)$ kabul edilmiştir. Tablo 3'e göre destekleyici pazar odaklılığındaki değişimin \% 33,7'si destekleyici örgüt kültüründen kaynaklandığ 1 , destekleyici destek kültüründeki bir birimlik artışı, pazar odaklılığını 0,711 birim arttırdığ belirlenmiştir. Destekleyici örgüt kültürünün otel işletmelerine yerleştirilmesinin pazar odaklılığ anlamında önemli olduğu ifade edilebilir.

Bürokratik örgüt kültürünün pazar odaklılığ etkisini belirlemek üzere oluşturulan üçüncü hipotez H3: "Bürokratik örgüt kültürü pazar odaklılığını negatif yönde etkiler" hipotezi $\% 5$ anlamll1ık düzeyinde $(\mathrm{p}=0,000)$ kabul edilmiştir. Bürokratik örgüt kültürünün pazar odaklılı̆ğ üzerinde negatif yönde bir etkisi olduğu tespit edilmiştir. Tablo 3'e göre Pazar odaklılığındaki değişimin \%25,2'sinin bürokratik örgüt kültüründen kaynaklandığı, örgüt kültüründeki bir birimlik değişimin pazar odaklılı̆̆ını -,468 birim azalttığı belirlenmiştir. Bürokratik örgüt kültürünün benimsenmesinin otellerin pazar odaklılığı açısından olumsuz bir etki gösterebileceği sonucuna ulaşılabilir.

\begin{tabular}{|c|c|c|c|c|c|c|c|c|c|c|}
\hline Hipotez & $\begin{array}{l}\text { Bağımsız } \\
\text { Değişken }\end{array}$ & Bağımlı Değiş̧ken & $\mathbf{R}$ & $\mathbf{R}^{2}$ & $\boldsymbol{\beta}$ & Std. $\beta$ & $\mathbf{t}$ & $\mathbf{F}$ & p & Sonuç \\
\hline H1 & $\begin{array}{l}\text { Yenilikçi Örgüt } \\
\text { Kültürü }\end{array}$ & Pazar odaklılığ & 0,656 & 0,431 & 0,892 & 0,656 & 12,514 & 156,594 & 0,000 & KABUL \\
\hline $\mathrm{H} 2$ & $\begin{array}{l}\text { Destekleyici Örgüt } \\
\text { Kültürrü }\end{array}$ & & 0,581 & 0,337 & 0,711 & 0,581 & 10,26 & 105,224 & 0,000 & KABUL \\
\hline H3 & $\begin{array}{l}\text { Bürokratik Örgüt } \\
\text { Kültürü }\end{array}$ & & $-0,502$ & 0,252 & $-0,468$ & $-0,502$ & $-8,351$ & 69,739 & 0,000 & KABUL \\
\hline
\end{tabular}

\section{Sonuçlar ve Öneriler}

$\mathrm{Bu}$ çalışmanın amacı otel işletmeleri bağlamında örgüt kültürü boyutlarının pazar odaklılığı üzerindeki etkilerini incelemektir. Çalışmada pazarlama araştırmaları göz önünde bulundurularak, yenilikçi ve destekleyici örgüt kültürlerine sahip otel işletmelerinin pazar odaklı yaklaşımı uygulamakta daha iyi konumlandırılacağı iddia edilmiştir. Çalışma sonucunda hipotezler desteklenmiş̧ir. Elde edilen bulgular doğrultusunda hem teorik ve hem de uygulamaya yönelik çıkarımlar sağlanmıştır. Teorik açıdan bakıldığında, çalışma örgüt külttürü boyutlarının pazar odaklılığı üzerindeki doğrudan ve dolaylı etkisini inceleyerek pazarlama teorisine katkıda bulunmuştur.

$\mathrm{Bu}$ çalışmanın sonuçlarına göre, kaynak tabanlı görünüm teorisinden yola çıkarak bazı örgüt kültürü boyutlarının otel işletmelerinde rekabet avantaj1 yaratmak için kullanılabilecek kaynaklar olabileceği söylenebilir. Özellikle elde edilen sonuçlar yenilikçi ve destekleyici kültür boyutlarının otel işletmelerinin rekabetçi konumunu güçlendiren ve böylece performansını artıracak kaynaklar olarak kullanılabileceğini ortaya koymaktadır. O'Cass ve Viet Ngo'nun (2007) çalışmasının sonuçları yenilikçi kültürün pazar odaklılı̆̆ için önemli bir önceliği olduğunu teyit etmektedir. Yazarların çalışması araştırmanın sonuçlarıyla paralellik göstermektedir.

Uygulama açısından bulgular otel işletmelerinin sahipleri/yöneticilerine rehberlik etmektedir. Bir örgütünmevcut kültürünün kolayca değiş̧tirilemeyeceği bir gerçektir. Fakat elde edilen sonuçlar otel işletmecilerinin destekleyici ve yenilikçi örgüt kültürleriyle ilişkili özellikleri benimsemeleri gerektiğini vurgulamaktadır. Yenilikçi kültür, pazar odaklılığın uygulanması veya konuşlandırılmasına hazırlıkta dikkat çekici bir rol oynamaktadır.

Çalışma sonuçları, pazar odaklılı̆̆ıyla ilişkili davranışların, yenilikçi ve destekleyici kültürlerle ilişkili özellikleri besleyerek kolaylaştırılabileceği söylenebilir. Yenilikçi kültür, yaratıcı, sonuç odaklı ve zorlu bir çalışma ortamına neden olmaktadır. Böyle bir kültürü geliştirmek, çalışanların inisiyatif almasını gerektirir ve müşteri ihtiyaçlarını karşılamak ve örgütün tepkisini artırmak için örgütsel olarak yeni ürün veya hizmet fikirleri üretme gücünü zorunlu kılabilir. Öte yandan, destekleyici kültür, güvenen, insan odaklı ve teşvik eden bir çalışma ortamına neden olmaktadır. Böyle bir kültürün teşvik edilmesi, örneğin, örgüt çapında iş birliğine olanak tanımak, tüm üyelerin deneyimleri ve yeteneklerini geliştirmek, çalışanların karar alma süreçlerine katılımını kolaylaştırmak, bilgi topluluğunu artırmak, müşteri ve rakip odaklılığı artırmak şeklinde gerçekleştirilebilir.

Tüm çalışmalarda olduğu gibi bu çalışmada da sınırlılıklar bulunmaktadır. $\mathrm{Bu}$ araştırmanın odak noktası, oldukça parçalanmış ve olgun bir sektörde faaliyet gösteren otel işletmeleridir. Gelecekteki araştırmalar, bu çalışmanın sonuçlarını diğer hizmet sektörleri üzerine araştırmalar yaparak genelleştirebilir. Çalışma, örgüt kültürü ve pazar odaklılığı olmak üzere iki yapının incelenmesi ile sınırlandırılmıştır. $\mathrm{Bu}$ sınırlamalara rağmen, bu çalışma, işletme kaynakları ve pazarlama süreçleri arasındaki ilişkiyi vurgulayarak hizmet sektörü literatürüne önemli katkı sağlamaktadır. Sonuçlar, otel işletmeleri için pazar odaklılı̆̆ uygulama aşamasında iç örgütsel ve yönetsel 
kaynakları geliștirme ve etkili bir şekilde kullanma gereksinimini vurgulamıştır. Çalışmanın sonuçları, otel için mevcut iç kaynakların geliştirilmesi ile örgüt kültürünün iyileştirilebileceğini önermektedir. Otel işletmelerinde yenilikçi ve destekleyici örgüt kültürünün geliştirilmesi gerektiği ve bu şekilde otellerin daha fazla pazar odaklı davranabileceği ifade edilmiştir.

\section{Kaynakça}

Anderson, E. W., Fornell, C., \& Rust, R. T. (1997). Customer satisfaction, productivity, and profitability: Differences between goods and services. Marketing Science, 16(2), 129-145.

Becherer, R. C., \& Maurer, J. G. (1997). The moderating effect of environmental variables on the entrepreneurial and marketing orientation of entrepreneur-led firms. Entrepreneurship Theory and Practice, 22(1), 47-58.

Becherer, R. C., Halstead, D., \& Haynes, P. J. (2003). Marketing orientation in SMEs: Effects of the internet environment. New England Journal of Entrepreneurship,6(1), 13-22.

Berson, Y., Oreg, S., \& Dvir, T. (2008). CEO values, organizational culture and firm outcomes. Journal of Organizational Behavior, 29(5), 615-633.

Chen, C. F., \& Myagmarsuren, O. (2013). Exploring the moderating effects of value offerings between market orientation and performance in tourism industry. International Journal of Tourism Research, 15, 595-610.

Chen, W. J. (2013). Factors influencing internal service quality at international tourist hotels. International Journal of Hospitality Management, 35, 152-160.

Deshpande, R., \& Farley, J. U. (2004). Organizationalculture, market orientation,innovativeness, and firm performance: An international research odyssey. International Journal of Research in Marketing, 21(1), 3-22.

Deshpande, R., Farley, J. U., \& Webster, F. E., Jr. (1993). Corporate culture, customer orientation, and innovativeness. Journal of Marketing, 57(1), 23-38.

Deshpande, R., \& Farley, J. U. (1998). Measuring market orientation: Generalization and synthesis. Journal of Market Focused Management, 2(3), 213-232.

Didonet, S., Simmons, G., Díaz-Villavicencio, G., \& Palmer, M. (2012). The relationship between small business market orientation and environmental uncertainty. Marketing Intelligence \& Planning, 30(7), 757-779.

Gao, Y. (2017). Business leaders' personal values, organisational culture and market orientation. Journal of Strategic Marketing, 25(1), 49-64.

Gebhardt, G. F., Carpenter, G. S., \& Sherry, John F., Jr. (2006). Creating a market orientation: A longitudinal, multifirm, grounded analysis of cultural transformation.Journal of Marketing, 70(4), 37-55.
Herrero, A., Collado, J., \&García de los Salmones, M. M. (2013). Market orientation and Manager's innovativeness in the adoption of managerial IT in small Firms:Application to there tail sector. The International Journal of Human Capital and Information Technology Professionals, 4(3), 58-75.

Ireland, R. D., Hitt, M. A., \& Sirmon, D. G. (2003). A model of strategic entrepreneurship: the construct and its dimensions. Journal of management, 29(6),963-989.

Jaworski, B. J., \&Kohli, A. K. (1993). Market orientation: Antecedents and consequences. Journal of Marketing, 57(3), 53-70.

Kirca, A. H., Jayachandran, S., \&Bearden, W. O. (2005). Market orientation: A meta analytic review and assessment of its antecedents and impact on performance. Journal of Marketing, 69(2), 24-41.

Kohli, A. K., \& Jaworski, B. J. (1990). Market orientation: The construct, research propositions, and managerial implications. The Journal of Marketing, 54(2), 1-18.

Leisen, B., Lilly, B., \&Winsor, R. D. (2002). The effects of organizational culture and market orientation on the effectiveness of strategic marketing alliances. The Journal of Services Marketing, 16(2), 201-222.

McClure, R. E. (2010). The influence of organizational culture and conflict on market orientation. The Journal of Business \& Industrial Marketing, 25(7), 514-524.

Narver, J. C., \&Slater, S. F. (1990). The effect of a market orientation on business profitability. Journal of Marketing, 54(4), 20-36.

O'Cass, A., \&Viet Ngo, L. (2007). Market orientation versus innovative culture: Two routes to superior brand performance. European Journal of Marketing, 41(7/8),868-887.

Parasuraman, A., Zeithaml, V. A., \& Berry, L. L. (1985). A conceptual model of service quality and its implications for future research. The Journal of Marketing, 49(4),4150 .

Pena, A. I. P., Jamilena, D. M. F., \& Molina, M. A. R. (2012). Market orientation as a strategy for the rural tourism sector: Its effect on tourist behavior and the performance of enterprises. Journal of Travel Research, 52(2), 225-239.

Pena, A. I. P., Jamilena, D. M. F., \& Molina, M. A. R. (2013). Impact of customer orientation and ICT use on the perceived performance of rural tourism enterprises. Journal of Travel \&Tourism Marketing, 30(3), 272-289.

Schein, E. H. (1997). Organizational culture and leadership. San Francisco, CA: Jossey-Bass.

Slater, S. F., \& Narver, J. C. (1998). Customer-led and market-oriented: Let's not confuse the two. Strategic Management Journal, 19(10), 1001-1006.

Smircich, L. (1983). Concepts of culture and organizational analysis. Administrative Science Quarterly, 28(3), 339358. 
Stokes, D., \& Blackburn, R. (1999). Entrepreneurship building for the future, working paper series. UK: Small Business Research Center, Kingston University.

Stokes, D. (2000). Entrepreneurial marketing: A conceptualisation from qualitative research. Qualitative Market Research, 3(1), 47-54..

Wallach, E. J. (1983). Individuals and organizations: The cultural match. Training and Development Journal, $37(2), 28-36$.

Wang, C. H., Chen, K. Y., \&Chen, S. C. (2012). Total quality management, market orientation and hotel performance: The moderating effects of external environmental factors. International Journal of Hospitality Management, 31(1),119-129.

Wu, J. J. (2004). Influence of market orientation and strategy on travel industry performance: An empirical study of e-commerce in taiwan. Tourism Management, 25(3), 357-365.

Yaprak, A., Tasoluk, B., \& Kocas, C. (2015). Market orientation, managerial perceptions, and corporate culture in an emerging market: Evidence from Turkey. International Business Review, 24(3), 443-456.

Zhou, K. Z., Brown, J. R., \& Dev, C. S. (2009). Market orientation, competitive advantage, and performance: A demand-based perspective. Journal of Business Research, 62(11), 1063-1070. 
